\title{
СОЦИАЛЬНОЕ ПРЕДПРИНИМАТЕЛЬСТВО КАК ДРАЙВЕР РАЗВИТИЯ СОЦИОКУЛЬТУРНОЙ СРЕДЫ МАЛЫХ ТЕРРИТОРИЙ
}

\begin{abstract}
В статье рассматривается вопрос о воздействии социальных инноваций, источниками которых являются проекты социального предпринимательства (СП) и гражданские инициативы, на развитие социокультурной среды малых территорий. Согласно исследованиям, социальные инновации влияют на развитие территории через создание новых возможностей для взаимодействия между значимыми акторами. Подобное взаимодействие приводит к улучшению коммуникации и росту способности к совместным действиям. Следствием также является изменение социального капитала, выраженное в росте сетей сотрудничества для решения общих проблем, возникновении социального партнерства и создании социально-инновационных экосистем. Статья основана на результатах полевого исследования, проведенного летом 2018 и 2019 гг., включающего 48 полуструктурированных интервью с участниками проектов и организаций в сфере культуры всех секторов экономики Волосовского и Лужского районов Ленинградской области, а также Каргопольского и Вельского районов Архангельской области. Исследование показало, что при наличии коор-
\end{abstract}

Светлана Борисовна Богуславская - к. э.н., аналитик, Центр прикладных исследований и разработок; ст.преп., департамент финансов, Национальный исследовательский университет «Высшая школа экономики», Санкт-Петербург, Россия. Электронная почта: sboguslavskaya@hse.ru

Ксения Алексеевна Кузьмина- Ph.D., доцент, департамент менеджмента, Национальный исследовательский университет «Высшая школа экономики», Санкт-Петербург, Россия. Электронная почта: kkuzmina@hse.ru

Надежда Васильевна Рождественская - к.э.н., доцент, кафедра отраслевой экономики и финансов, Институт экономики и управления, Российский государственный педагогический университет им. А.И. Герцена, Санкт-Петербург, Россия. Электронная почта: nrozhdestvenskaia@herzen.spb.ru 
динирующего внешнего воздействия происходит переход к системному стратегическому сотрудничеству между СП. Уникальность формируемых СП отношений состоит в том, что в них между акторами одновременно имеет место и партнерство, не подразумевающее прагматических целей, и бизнес-партнерство. Бизнес-модели СП в культурной сфере нередко строятся на кооперации и создании комплементарных товаров и услуг по отношению к другим проектам, работающим на малой территории. Сети, формируемые СП, включают различных акторов, что приводит к формированию устойчивых экосистем. На культурных мероприятиях и постоянно действующих площадках, организованных СП, взаимодействуют социальные проекты, малый бизнес, СП и жители территории. Эта среда действительно формирует у участников новые модели поведения, за счет которых создаются партнерские связи. Поэтому потенциально СП является существенным фактором развития социокультурной среды малых территорий, однако степень этого влияния можно выяснить лишь при проведении более долгосрочных исследований.

Ключевые слова: социальное предпринимательство, гражданские инициативы, культурные проекты, развитие территорий, социальное партнерство

DOI: 10.17323/727-0634-2021-19-1-85-100

В России стратегии развития малых территорий, социальное воспроизводство, социально-экономическое развитие, социальное проектирование (Маркин, Черныш 2019; Карпова, Прянишников 2016) - небольшой круг актуальных тем, редко поднимаемых исследователями. Особое место занимает вопрос развития малых территорий через социальные инициативы и проекты в сфере культуры и сохранения традиций и ремесел, в т. ч. посредством социального предпринимательства. В соответствии с Федеральным законом № 209-Ф3 (2007) к СП относится культурно-просветительская деятельность, включая деятельность частных музеев, театров, библиотек, архивов, школ-студий, творческих мастерских, ботанических и зоологических садов, домов культуры, домов народного творчества. Федеральный закон № 245-Ф3 (2019) внес ряд поправок, закрепив понятия «социальное предпринимательство» и «социальное предприятие» за представителями малого и среднего бизнеса, выполняющими определенные виды деятельности в социальной сфере или самой своей деятельностью решающими социальные проблемы.

Сами акторы, действующие в этом поле, трактуют СП шире-как деятельность, направленную на решение или смягчение социальных проблем общества на условиях самоокупаемости и устойчивости, т.е. на бизнес-модели (Наше будущее 2019). Такое определение позволяет анализировать СП как с точки зрения социальных эффектов и их влияния на решение проблем, так и с точки зрения созданных бизнес-механизмов и экономических возможностей. СП может стать звеном, которое возникает 
в результате развития партнерства государства, бизнеса и инициатив в социальной сфере и сфере культуры.

Авторами поставлен вопрос о необходимых условиях, при которых СП могут влиять на развитие социокультурной среды малых территорий. Для ответа на вопрос были проанализированы интервью с людьми, вовлеченными в реализацию СП. Проверена гипотеза о том, что для существенного влияния на социокультурную среду СП необходимо создание экосистемы для развития партнерства, укрепление бизнес-моделей и высокая степень включенности в решение проблем территории.

\section{Социальное предпринимательство В контексте развития территорий}

В рамках данного исследования под социокультурной средой понимается совокупность возможностей и способов удовлетворения жителями их культурных потребностей, культурного и исторического наследия малой территории, ценностей, традиций, установок в культурной сфере, акторов и способов их взаимодействия. Развитие социокультурной среды означает расширение возможностей для удовлетворения культурных потребностей жителей, появление новых акторов и новых способов коммуникации между ними, а также изменения формальных и неформальных институтов в сфере культуры. На малых территориях (с населением менее 100 тыс. чел.) в России важнейшими акторами, формирующими социокультурную среду, являются государственные учреждения культуры и досуга. К основным проблемам работы таких учреждений относятся неудовлетворительное состояние зданий, низкая материально-техническая оснащенность, недостаток высококвалифицированных кадров, устаревшие формы и методы работы с населением (Маркин, Черныш 2019). Учреждения культуры на малых территориях обеспечивают в основном вовлеченность детей, подростков и пенсионеров, упуская остальные возрастные группы населения. Недостаточность существующих возможностей подталкивает к поиску новых форматов и форм взаимодействия не только с подведомственными учреждениями культуры и досуга-в ответ на запросы возникают гражданские инициативы и проекты СП.

Низовые социальные инициативы могут играть существенную роль в развитии малых территорий. В мировой практике накоплен опыт развития сельскохозяйственных регионов путем поддержки местных гражданских инициатив (Eardley, Vincent 2011) и развития социальных инноваций (Bosworth et al. 2016; Neumeier 2017; Ulug, Horlings 2019). В России влияние гражданских инициатив на развитие малых территорий исследуется в контексте устойчивого развития: проблемы плотности гражданских институтов, роль социального партнерства в развитии территорий (Нуттунен и др. 2018, Третьякова и др. 2015), развитие территориальных общностей (Дроздова 2019),основа для понимания результатов деятельности СП. 
В числе положительных эффектов социальных инноваций СП выделяют повышение качества жизни, рост творческого потенциала жителей (Neumeier 2017:37), повышение общего уровня удовлетворенности (Ulug, Horlings 2019). Но наиболее важным для развития территории являются улучшение коммуникации (Cummings et al. 2018), рост способности к совместным действиям, в т.ч. людей с разным статусом и социальным опытом (Neumeier 2017:37), увеличение числа социальных контактов (Cummings et al. 2018). В результате происходит изменение качества социального капитала (Ulug, Horlings 2019: 163; Bosworth et al. 2016:444), что выражается в преобразовании и совершенствовании институтов, социальных сетей и норм поведения (Гончаров 2014: 132). В свою очередь, рост социального капитала работает как предпосылка для новых социальных инноваций, на малой территории развиваются сети сотрудничества для решения общих проблем и социальное партнерство (Копотева, Никула 2008), могут быть сформированы социально-инновационные экосистемы (Соловьева 2019). Так, формируются территориальные общности, объединенные устойчивым социальным взаимодействием и практиками взаимной поддержки (Дроздова 2019; Ulug, Horlings 2019: 151).

Для устойчивого эффекта деятельности СП на малых территориях им необходима информационная, проектная и обучающая поддержка (Третьякова и др. 2015:37), которая может оказываться как со стороны местных властей, так и со стороны ресурсных центров, ассоциаций и просто опытных коллег (Cummings et al 2018). Социальное влияние будет ощутимо, если создана инфраструктура, способная придавать импульс новым социальнокультурным практикам. Среди них - образовательные и просветительские проекты, трендовые культурные события и фестивали, организуемые активистами, новые продукты, созданные социальными предпринимателями. Устойчивый эффект от деятельности СП возможен только при включении различных групп местного сообщества и при достижении изменений в самом сложном типе отношений- институциональной среде, мышлении и моделях взаимодействий на малых территориях. В результате анализа российских и иностранных источников можно сделать вывод о том, что СП способствует успешному неоэндогенному развитию малых территорий (Neumeier 2017: 37; Baker, Mehmood 2015: 11), связанному с созданием институтов развития и саморазвития, с формированием социального капитала на местах. СП развивает сети, финансовый, информационный и институциональный потенциал территории (Костяев 2018). В частности, за счет проектов СП развивается и социокультурная среда территории.

\section{Экосистема социального предпринимательства на малых территориях}

Статья основана на результатах полевого исследования, проведенного летом 2018 и 2019 гг., включающего 48 полуструктурированных интервью 
с участниками проектов и организаций Волосовского и Лужского районов Ленинградской области, Вельского и Каргопольского районов Архангельской области. Выбор районов обусловлен их относительной удаленностью от регионального центра. Выборка формировалась методом снежного кома, а в случае интервью с представителями администраций и государственных учреждений области культуры в выборку вошли все доступные и давшие согласие на беседу сотрудники. Основными темами интервью были участие бизнеса и НКО в культурной и социальной жизни малых территорий, изменения, произошедшие в социальной и культурной жизни за последние 3 года5 лет; взаимодействие акторов разных организационно-правовых форм.

На основе результатов полевых исследований проанализирована плотность связей между проектами. Разнообразие форм и направлений деятельности респондентов позволило получить многомерные данные о месте и роли СП на выбранных территориях, а включение в выборку организаций государственного сектора было обусловлено необходимостью определения их отношения к новым акторам социокультурной среды. Согласно анализу интервью, СП занимает особое место в социокультурной среде малых территорий, оно органически связано с работой государственных учреждений в сфере культуры. Зачастую именно на их базе развиваются идеи, которые становятся отдельными гражданскими инициативами и иногда перерастают в проекты СП. Например, на базе детского кружка в Доме культуры г. Луга появился Семейный клуб сохранения народных традиций «Любочажье» $(15 ;$ здесь и далее см. материалы для анализа по номеру) и онлайн-школа «Русская роспись» (11).

Внутри сообщества СП и гражданских инициатив во всех районах отмечается взаимодействие и поддержка. Например, в Лужском районе клуб «Любочажье» принимает участие в мероприятиях, проводимых Музеем «Деревня Псоедь» (7), который, в свою очередь, рекомендует для питания и ночлега местное крестьянско-фермерское хозяйство (5). Между этими акторами одновременно есть и партнерство, основанное на ценностях, не подразумевающее прагматических целей, и бизнес-партнерство, при этом с учетом специфики каждого проекта конкуренции между ними не наблюдается. В то время как государственные учреждения культуры и досуга частично конкурируют друг с другом за свою целевую аудиторию, конкуренции между ними и социальными предпринимателями в интервью не обнаруживается, также как нет и конкуренции между самими инициативами: «У нас материала столько, что хватит на всех, не стоит из-за этого конкурировать» (Информант 1). СП проекты и гражданские инициативы гармонично встраиваются в мероприятия, проходящие при поддержке администрации, на базе и при участии государственных учреждений.

В двух из четырех рассматриваемых районах произошел переход от ситуационного взаимодействия между СП и другими акторами к системному стратегическому сотрудничеству. Оно становится возможным 
благодаря координирующим организациям, которые целенаправленно помогают взаимодействию и развитию СП и гражданских инициатив. В Волосовском районе эту роль взяло на себя АНО РИТКО «Творческие проекты Кайкино» (1), а в Каргопольском - Региональная Ассоциация общественных организаций Каргопольского района (13).

На рисунке 1 показана плотность связей между акторами в Лужском (нет координирующего центра) и Каргопольском (есть координирующий центр) районах. Плотность связей определялась на основании данных интервью и открытых источников (сайтов организаций, их страниц в социальных сетях и публикаций о мероприятиях, где они принимали участие). Размер сети каждого района учитывал представителей государственных учреждений, СП и гражданских инициатив. Для визуализации использовалась лучевая векторная диаграмма MS Excel. В основе- попарные связи акторов района, прочности которых присваивалось значение 2 при периодическом взаимодействии, 1 - при эпизодическом и 0 - если взаимодействие не выявлено, что отражено разницей в линиях. В зависимости от роста числа и прочности связей увеличивался и шрифт в названии акторов.

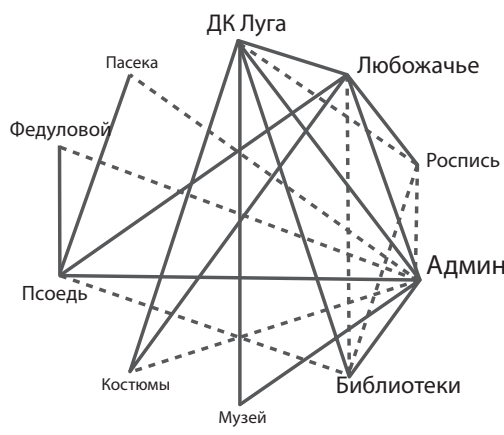

Лужский район

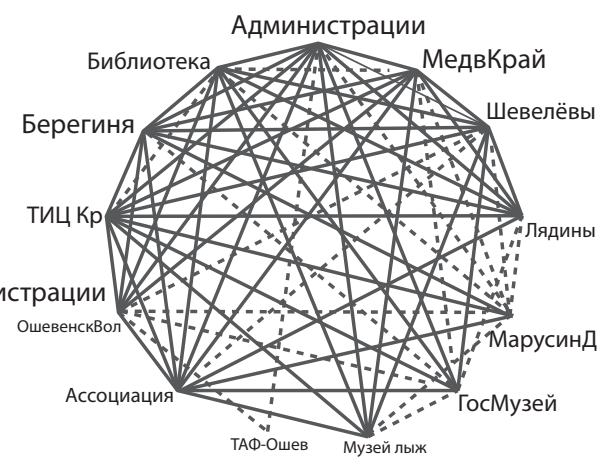

Каргопольский район

\footnotetext{
...... в взаимодействие носит эпизодический характер

взаимодействие носит постоянный характер

размер шрифта увеличивается с ростом количества связей
}

Рисунок 1. Плотность связей между акторами социокультурной среды

В Каргопольском районе более плотная система взаимосвязей между представителями социокультурной сферы, что позволяет предположить долгосрочное устойчивое развитие социокультурной среды на территории. Инфраструктура поддержки СП проектов и гражданских инициатив в данном случае шире и разнообразнее, большее число участников может поделиться опытом, а наличие ежегодных совместных мероприятий дает возможность включения новых проектов. Ресурсные центры, обучающие навыкам пред- 
принимательства, бизнес-планирования и социального проектирования, не просто предоставляют ресурс, но и увеличивают количество связей между акторами, тем самым поддерживая устойчивость СП, что позволяет проявиться позитивным эффектам, влияющим на развитие территорий.Во всех районах источниками финансовой поддержки являются программы устойчивого развития сельских территорий: программа Корпорации развития в Архангельской области, субсидии для крестьянско-фермерских хозяйств, поддержка Фонда президентских грантов и благотворительных фондов. В Архангельской области развита грантовая система поддержки проектов территориальных общественных самоуправлений $(21,25)$. Значимое влияние фондов очевидно- большинство успешных проектов один или несколько раз получали гранты $(1,7,25)$, а Музей Шевелевых (9) был одним из первых получателей президентского гранта. Функционируют также ресурсные центры, которые занимаются развитием предпринимательской деятельности и творческих индустрий на малых территориях, организуют семинары и мастер-классы для НКО, СП, сотрудников учреждений культуры $(1,13)$. Проекты СП оказывают влияние на развитие социокультурной среды, когда они работают в условиях развитой экосистемы. Наличие экосистемы также повышает финансовую устойчивость проектов. Инициативы в сфере культуры постепенно могут приобрести сильную бизнес-модель, однако не все учредители считают правильным развиваться именно в коммерческой сфере. У групп проектов по направлениям деятельности можно выделить специфические признаки бизнес-моделей.

\section{Бизнес-модели социального предпринимательства в культурной сфере}

СП на малых территориях работают в определенных нишах, обычно не занятых государственными учреждениями. Бизнес-модели этих проектов имеют ярко выраженные особенности, описанные ниже.

Сохранение традиций и возрождение ремесел. Деятельность таких проектов основана на изготовлении и продаже произведений ремесел и народного творчества, а также на проведении обучающих курсов и мероприятий $(1,9,25)$. Проекты, направленные на сохранение традиций, зачастую используют современные технологии для производства и продвижения. Так, в Лужском районе успешно работает онлайн-школа традиционных видов росписи (11), а «Кайкино» (1) является центром инноваций и инфраструктурной поддержки СП проектов района. С помощью своей деятельности они стремятся сохранить культурное наследие, вовлечь население в творческие виды деятельности, повысить узнаваемость территории, развить инфраструктуру поддержки новых и существующих инициатив.

Сохранение памятников культуры, деревень, включая размещение и другие туристические услуги. Проекты этого направления отвечают 
за досуг населения и туристов. Они могут быть более активны в определенный сезон $(6,7)$ или работать круглогодично $(2,21,25)$. Бизнес-модели проектов строятся на оказании досуговых услуг, иногда услуг размещения. Сопутствующим направлением является экспозиционная деятельностьпроведение выставок картин и фотографий, показы музейных коллекций $(8,14)$. Почти все проекты занимаются продажей сувенирной продукции. Среди социальных эффектов можно выделить развитие возможностей проведения досуга, в т. ч. семейного, сохранение и возрождение памятников культуры, сохранение исторической памяти.

Организация культурно-массовых мероприятий. Ежегодные крупные мероприятия, такие как ярмарки, фестивали, праздники народных мастеров, являются традиционным способом продвижения продукции СП $(17,18,19)$. Дома-музеи часто принимают участников мероприятия. Эти события являются знаковыми для местных и окрестных жителей, часть выходит на междугородный и международный уровень, привлекая туристов и развивая интерес к территории. Кроме того, мероприятия-это площадки, где социальные проекты, малый бизнес, СП и жители региона могут познакомиться друг с другом и найти возможности для взаимодействия (20).

Возрождение сельского хозяйства. Данное направление представлено в основном малыми семейными предприятиями, возрождающими земледелие и скотоводство. Они создают рабочие места, и, с помощью грантов, влияют на развитие инфраструктуры, привносят на территорию новые продукты и технологии $(5,10)$. В отдельных случаях сельскохозяйственные проекты сочетают сельскохозяйственную и спортивно-туристическую деятельность (5). СП и гражданские активисты сохраняют историю, вовлекают жителей в сохранение и возрождение традиций, а также создают продукты и услуги, увеличивающие известность места и привлекающие туристов, создают среду, способствующую сохранению и развитию территорий.

Именно бизнес-модели являются важным фактором устойчивости СП в сфере культуры. Возможность самостоятельно зарабатывать и привлекать ресурсы дает им право определять направление развития, способы работы и взаимодействия, не будучи ограниченными одним источником средств: «Мы стараемся сделать так, чтобы наши проекты приносили хотя бы какой-то доход, который можно вложить в дальнейшее развитие, потому что за счет грантовых историй не выжить» (Информант 1). Чем больше они используют собственные финансовые средства, тем более они независимы.

\section{Потенциал социального предпринимательства и развитие социокультурной среды}

Благодаря устойчивым бизнес-моделям СП способны продвигать проекты, меняющие социокультурную среду. Они создают новые формы и способы удовлетворения потребностей местных жителей: «Если какого-то 
сервиса нет в малом городе, это не значит, что людям он не нужен <... Хоть «Динозаврию» открой, хоть заводы, главное, что мы должны понимать, что вы должны решать проблему» (Информант 2). Экопарк «Медвежий край» в г. Каргополь стал не только туристическим местом, но и решил одну из основных проблем- создал дополнительную возможность для проведения досуга и отдыха: «Для жителей появилось новое место, куда можно приводить своих гостей, наравне с осмотром достопримечательностей, а часть посетителей начинают свое знакомство с Каргополем именно с экопарка» (Информант 3).

Участие в проектах СП формирует у жителей- потребителей услуг новые модели поведения: «Если несколько лет назад люди стеснялись участвовать в играх, народных танцах и пр., то теперь достаточно легко вовлекаются и с интересом участвуют, привыкли» (Информант 4). Улучшение коммуникаций, совместные действия, в т.ч. в культурных проектах, приводят к улучшению качества человеческого капитала. В долгосрочной перспективе следствием этого может стать уменьшение оттока жителей из малых территорий: «Дети, воспитанные в «Любочажье», чаще других возвращзаются жить в Лугу после учебы» (Информант 4).

СП служит драйвером развития гражданских инициатив и создает условия для партнерской работы проектов: «Эти проекты научили нас работать в партнерстве, объединяться, привлекать дополнительное финансирование... дали нам новые знакомства, в т.ч. экспертные» (Информант 1). Синергия работы муниципальных учреждений культуры и социально-предпринимательских инициатив дает новые проекты, которые становятся местом притяжения и появления новых экономических возможностей. Возникновение и развитие сетей партнерств в изучаемых районах происходит при создании общественных организаций $(1,13)$, взаимодействии инициатив в рамках фестивалей $(19,20)$, а также при наличии объединяющих проектов $(7,15,25)$.

Успешный опыт и распространение информации о нем дает импульс для создания других проектов: «Предпринимателям нужна больше не денежная поддержка, а информационная, чтобы о них говорили, чтобь они были на слуху, чтобы на них равнялись» (Информант 2). Своим примером предприниматели показывают, что идеи работают. Так, после открытия детского центра «Динозаврия» в Вельске появились другие детские центры и клубы. При этом местная администрация получает свои выгоды от гражданских инициатив и СП, т.к. их деятельность решает многие социальные вопросы в районе: «Понимание главой района важности мероприятий помогает развиваться городу, гостиницы полные, выручка возрастает, работают таксистыл» (Информант 2). Активный глава администрации, применяя экосистемный подход в работе, способствует продвижению лучших практик, помогает расширению бизнеса и проведению мероприятий. 
Потенциал СП для развития малых территорий заложен в импульсе появления новых проектов на основе партнерских сетей и апробированных бизнес-моделей, показавших свою эффективность и жизнеспособность.

\section{Заключение}

Сложившаяся на малых территориях социокультурная среда, формируемая по большей части муниципальными бюджетными организациями, постепенно меняется за счет появления гражданских инициатив и СП. Основным фактором развития является партнерство между стейкхолдерами для создания единой экосистемы. Происходящие в результате изменения человеческого капитала (ценностей, привычек, поведения, физического и душевного благополучия) и изменения в жизни людей (повышение благосостояния, улучшение инфраструктуры) становятся основой для развития малых территорий в долгосрочной перспективе.

Развитию СП на малых территориях способствуют возможность получения первоначальной финансовой поддержки (гранты, субсидии, кредиты), наличие ресурсных центров и интеграционных площадок. Собственные бизнес-модели становятся источником долгосрочного развития и финансовой независимости проектов. Изученные бизнес-модели СП в сфере культуры на малых территориях имеют отличия в зависимости от присущего району потенциала и потребностей жителей. В Лужском районе это проекты, связанные с возрождением сельского хозяйства и сохранением традиций, в Каргопольском- инициативы по сохранению культурного наследия, ремесел и проведения досуга, в Волосовском - фестивали и арт-пространства, в Вельском активнее СП, связанные с организацией семейного досуга. Возможным негативным фактором, мешающим развитию СП в культурной сфере, может стать относительно долгий возврат инвестиций. Хотя проекты СП легче адаптируются под потребности аудитории, по сравнению с организациями государственного сектора, они менее финансово устойчивы.

Результаты социального влияния гражданских инициатив и СП в сфере культуры на малых территориях заметны, когда стейкхолдеры открыты для поиска решений и кооперации. В этой связи актуальна работа по продвижению положительных результатов и успешных примеров в качестве системных, а не только уникальных возможностей. В конечном счете успешные проекты СП, решающие потребности местных жителей, становятся основой для неоэндогенного развития малых территорий.

\section{Список информантов}

(Указаны только те информанты, чьи цитаты приведены в тексте работы)

Информант 1 - Региональная Ассоциация общественных организаций Каргопольского района. 
Информант 2 - ДРЦ «Динозаврия» в г. Вельск.

Информант 3 - Экопарк «Медвежий край» в г. Каргополь.

Информант 4- Клуб сохранения русских традиций «Любочажье».

\section{Материалы для анализа}

1. АНО РИТКО «Творческие проекты Кайкино». Доступно по ссылке: http://creaprok.com/

2. ДРЦ «Динозаврия». Доступно по ссылке: https://vk.com/dinozavriya_velsk

3. Культурный центр «Извара 15». Доступно по ссылке: https://vk.com/ public181408218; https://www.facebook.com/IZVARA15/

4. Креативное пространство «Марусин дом». Доступно по ссылке: https://vk.com/kargopolmarusindom

5. Крестьянско-фермерское хозяйство И. Федуловой. Доступно по ссылке: https://www.rusprofile.ru/ip/312471024000039

6. Мастерская «ТАФ-Ошевенск». Доступно по ссылке: https://vk.com/taf_oshevensk

7. Музей «Деревня Псоедь». Доступно по ссылке: http://psoed.ru/

8. Музей лыж. Доступно по ссылке: http://kargopoltic.ru/index.php/interesnye-mesta/muzej-lyzh

9. Музей мастеров Шевелевых и Каргопольской глиняной игрушки. Доступно по ссылке: https://www.facebook.com/MuzejMasterovSevelevyhIKargopolskojIgrus ki/community/

10. Общественная организация «Биодинамика». Доступно по ссылке: http://biodinamikaspb.ru/

11. Онлайн-школа «Русская роспись». Доступно по ссылке: https://folkartstudia.ru/wpm/startclub/

12. Пасека в деревне Новоселье. Доступно по ссылке: http://psoed.ru/в-музее-появилась-новая-эксурскурсия/\#more-1040

13. Региональная Ассоциация общественных организаций Каргопольского района. Доступно по ссылке: https://vk.com/kargopol_nko

14. РОО «Вельская картинная галерея». Доступно по ссылке: https://www.rusprofile.ru/id/7624758

15. Семейный клуб сохранения русских народных традиций «Любочажье». Доступно по ссылке: https://vk.com/club21591975

16. Студия этнодизайна «Фекла». Доступно по ссылке: https://luga.ru/social/cultura/ domcult

17. Событие: Ежегодный традиционный фестиваль «Кириллов день». Доступно по ссылке: https://vk.com/club121212067

18. Событие (ежегодное): гастрономический фестиваль «Баранье воскресенье». Доступно по ссылке: https://vk.com/prazdnikbarana

19. Событие (ежегодное)«Праздник народных мастеров России». Доступно по ссылке: https://vk.com/kargopol2019tic (актуально в 2020 г.) 
20. Событие: Фестиваль «Городской пикник» в г. Волосово. Доступно по ссылке: https://vk.com/volosovo.fest

21. ТОС «Лядинский круг» (Постоялый двор Лядинская Трапеза). Доступно по ссылке: http://www.kargopolland.ru/prochaja_inf/tos/ptos/tos__ljadinskij_krug_

22.Музей «Лядинские узоры». Доступно по ссылке: http://kargopoltic.ru/index.php/ interesnye-mesta/muzej-lyadinskie-uzory

23. Центр народных ремесел «Берегиня». Доступно по ссылке: https://cnrbereginya. arkh.muzkult.ru/news/49107163

24.Центр традиционной и народной культуры «Берендей». Доступно по ссылке: https://vk.com/velskmasta

25. Экопарк «Медвежий край». Доступно по ссылке: https:/vk.com/club28479088

26. Этнографический музей «Ошевенская волость». Доступно по ссылке: http:// www.kargopolland.ru/culture/news/805

\section{Список источников}

Гончаров Г.А. (2014) Взгляд на термин «социальные инновации» через призму концепции социального капитала. Вестник ВГУ. Серия: Экономика и управление, (2): $130-133$.

Карпова О.В., Прянишников Н.Е. (ред.) (2016) Социальная экономика локального: сборник научных статей. М.: МВШСЭН.

Копотева И. В., Никула Й. (2008) Социальные инновации в изменяющейся сельской среде России. Экономические и соииальные перемены: факты, тенденции, прогноз, 2 (2): $74-84$.

Костяев А.И. (2018) Концептуальные подходы к развитию сельских территорий с учетом европейского опыта. Аграрная наука Евро-Северо-Востока, 67 (6): 141-148.

Маркин В. В., Черныш М.Ф. (ред.) (2019) Малье города в соииальном пространстве России. Доступно по ссылке https://www.isras.ru/index.php?page_id=1198\&id=7751 (дата обращения: 11 апреля 2020).

Нуттунен П. А., Попова А. Л., Канавцев М.В. (2018) Роль социального партнерства в развитии территорий. Известия СПбГАУ, 50 (1): 170-174.

Соловьева Т.С. (2019) Теоретические аспекты формирования и развития региональных социально-инновационных экосистем. Вестник НГИЭИ, 3 (94): 84-93.

Третьякова Л.А., Целютина Т.В., Подвигайло А. А., Сапрыка В. А. (2015) Институты гражданского общества как инструмент устойчивого регионального развития. Региональная экономика: теория и практика, 407 (32): 18-30.

Федеральный закон (2007) О развитии малого и среднего предпринимательства в Российской Федерации, N 209-ФЗ от 24.07.2007.

Федеральный закон (2019) О внесении изменений в Федеральный закон «О развитии малого и среднего предпринимательства в Российской Федерации» в части закрепления понятий «соииальное предпринимательство», «сочиальное предприятие», N 245-Ф3 от 26.07.2019. 
Bosworth G., Rizzo F., Marquardt D., Strijker D., Haartsen T., Aagaard T. (2016) Identifying Social Innovations in European Local Rural Development Initiatives. Innovation: The European Journal of Social Science Research, 29 (4): 440-459.

Baker S., Mehmood A. (2015) Social Innovation and the Governance of Sustainable Places. Local Environment, 20 (3): 321-334.

Cummings S., Seferiadis A. A., Maas J., Bunders J.F. G., Marjolein Zweekhorst B. M. (2018) Knowledge, Social Capital, and Grassroots Development: Insights from Rural Bangladesh Pages Available at: https://www.tandfonline.com/doi/full/10.1080/00220388.2017.1417584\#_ i7 (accessed 17 May 2020).

Eardley A., Vincent P. (2011) Making the Most of Community Led Planning: A Best Practice Guide for Local Authorities, Action with Communities in Rural England (ACRE). Available at: http://www.communityplanning.net/pub-film/pdf/MakingTheMostOfCommunityLedPlanning.pdf (accessed 3 December 2019).

Neumeier S. (2017) Social Innovation in Rural Development: Identifying the Key Factors of Success. The Geographical Journal, 183 (1):34-46.

Ulug C., Horlings L. G. (2019) Connecting Resourcefulness and Social Innovation: Exploring Conditions and Processes in Community Gardens in the Netherlands. Local environment, 24 (3): 147-166. 
Svetlana Boguslavskaya, Ksenia Kuzmina, Nadezhda Rozhdestvenskaia

\title{
SOCIAL ENTREPRENEURSHIP AS A DEVELOPMENT DRIVER IN THE SOCIOCULTURAL ENVIRONMENT OF SMALL TERRITORIES
}

\begin{abstract}
The paper discusses the influence that social innovations based on social entrepreneurship projects have over the sociocultural environment of small territories. Social innovations have become a known development driver in small territories by providing new opportunities for interaction between actors. This has resulted in improved communication and increased capacity for joint action. Growing cooperation networks address common issues, promote social partnership and help create new socio-innovative ecosystems, thus contributing to social capital. For this paper, we analysed semi-structured interview data collected during a field study of 2018-2019 in Volosovsky and Luzhsky districts, Leningrad region, and Kargopolsky and Velsky districts, Arkhangelsk region. We interviewed representatives of forty-eight governmental and non-governmental cultural projects and organizations in all economic sectors. The study revealed that systemic strategic collaboration between social entrepreneurs takes place with coordinating external influence. Business partnership and collaboration with no pragmatic reason develop simultaneously. This developing interrelationship between such actors is unique. Social entrepreneurship business models in small territories often include cooperation with other projects and offer complimentary products and services. Cooperation networks formed by social entrepreneurs actually include various actors, which leads to sustainable ecosystems. Cultural events and permanent platforms organized by social entrepreneurs are places where social projects, small businesses and residents of the territories all interact together. This environment forms new behaviour patterns that create new partnerships. We recognize the potential of social entrepreneurship to become a more substantial development driver in small territories, but more longterm studies are required in this matter.
\end{abstract}

Key words: social entrepreneurship, civil initiatives, social partnership, cultural projects, the territory development, social results

DOI: $10.17323 / 727-0634-2021-19-1-85-100$

\footnotetext{
Svetlana Boguslavskaya- Cand. Sci (Econ.), Analyst, Centre for Applied Research and Development; Senior Lecturer, Higher School of Economics, Saint Petersburg, Russian Federation. Email: sboguslavskaya@hse.ru
}

Ksenia Kuzmina - PhD, assistant professor, Department of Management, Higher School of Economics, Saint Petersburg, Russian Federation. Email: kkuzmina@hse.ru

Nadezhda Rozhdestvenskaia- Cand. Sci (Econ.), assistant professor, Institute of Economics and Management, Herzen State Pedagogical University of Russia, Saint-Petersburg, Russian Federation. Email: nrozhdestvenskaia@herzen.spb.ru 


\section{References}

Baker S., Mehmood A. (2015) Social Innovation and the Governance of Sustainable Places. Local Environment, 20 (3): 321-334.

Bosworth G., Rizzo F., Marquardt D., Strijker D., Haartsen T., Aagaard T. (2016) Identifying Social Innovations in European Local Rural Development Initiatives. Innovation: The European Journal of Social Science Research, 29 (4): 440-459.

Cummings S., Seferiadis A. A., Maas J., Bunders J.F. G., Marjolein Zweekhorst B. M. (2018) Knowledge, Social Capital, and Grassroots Development: Insights from Rural Bangladesh Pages Available at: https:/www.tandfonline.com/doi/full/10.1080/00220388.2017.1417584\# 17 (accessed 17 May 2020).

Drozdova Ju.A. (2019) Resursnyj podhod v issledovanii territorial'nyh obshhnostej [A Resource Approach Towards Examining Territorial Communities]. Vestnik Instituta sociologii [Bulletin of the Institute of Sociology], 10 (1): 82-103.

Eardley A., Vincent P. (2011) Making the Most of Community Led Planning: A Best Practice Guide for Local Authorities, Action with Communities in Rural England (ACRE). Available at: http://www.communityplanning.net/pub-film/pdf/MakingTheMostOfCommunityLedPlanning.pdf (accessed 3 December 2019).

Elena and Gennady Timchenko Charitable Foundation (2019) Kul'turnaja mozaika: malye territorii-bol'shie vozmozhnosti [Cultural Mosaic: Small Localities, Big Opportunities]. M.: 'Prospekt'.

Goncharov G. A. (2014) Vzglyad na termin 'sotsial'nye innovatsii' cherez prizmu kontseptsii sotsial'nogo kapitala [Social Innovations: a look through the lens of Social Capital concept]. Vestnik VGU.Economics and management [Scientific journal Proceedings of Voronezh State University. Economics and management], (2): 130-133.

Karpova O. V., Prjanishnikov N.E. (eds.) (2016) Social'naja jekonomika lokal'nogo: sbornik nauchnyh statej [Social Economy of the Local Territories]. Moscow: MHSSES.

Kopoteva I. V., Nikula Y. (2008) Sotsial'nye innovatsii v izmenyayushcheysya sel'skoy srede Rossii [Social Innovations in a Changing Rural Environment of Russia]. Ekonomicheskie i sotsial'nye peremeny: fakty, tendentsii, prognoz [Economic and Social Changes: Facts, Trends, Forecast], 2 (2): 74-84.

Kostjaev A.I. (2018) Konceptual'nye podhody k razvitiju sel'skih territorij s uchetom evropejskogo opyta [Conceptual Approaches to the Development of Rural Areas, Taking into Account the European Experience]. Agrarnaja nauka Evro-Severo-Vostoka [Agricultural Science Euro-North-East], 67 (6): 141-148.

Markin V.V., Chernysh M.F. (eds.) (2019) Malye goroda v social'nom prostranstve Rossii [Small Towns in the Social Space of the Russian Federation]. Available at: https:/www. isras.ru/index.php?page_id=1198\&id=7751 (accessed 11 April 2020).

Neumeier S. (2017) Social Innovation in Rural Development: Identifying the Key Factors of Success. The Geographical Journal, 183 (1):34-46.

Nuttunen P. A., Popova A. L., Kanavcev M. V. (2018) Rol' social'nogo partnjorstva v razvitii territorij [Role of Social Partnership in the Process of Territorial Development]. Izvestija SPbGAU [Isvestiya Saint-Petersburg State Agrarian University], 50 (1): 170-174. 
Federal'nyj zakon (2007) O razvitii malogo i srednego predprinimatel'stva v Rossijskoj Federacii [Small and Medium Enterprise Development in the Russian Federation], N209FZ, from 24.07.2007.

Federal'nyj zakon (2019) O vnesenii izmenenij v Federal'nyj zakon 'O razvitii malogo $i$ 'social'noe predprinimatel 'stvo', 'social 'noe predpriyatie' [On Amendments to the Federal Law 'Small and Medium Enterprise Development in the Russian Federation in Concepts of "Social Entrepreneurship", "Social Enterprise"'], N 245-FZ, from 26.07.2019.

Solov'eva T.S. (2019) Teoreticheskie aspekty formirovaniya i razvitiya regional'nykh sotsial'noinnovatsionnykh ekosistem [Theoretical Issues of Social Innovation Ecosystems-building and Development]. Vestnik NGIEI [Bulletin NGIEI], 3 (94): 84-93.

Tret'jakova L.A., Tselyutina T. V., Podvigailo A. A., Sapryka V. A. (2015) Instituty grazhdanskogo obshhestva kak instrument ustojchivogo regional'nogo razvitija [Civil Society Institutions as a Tool for Sustainable Regional Development]. Regional'naja jekonomika: teorija i praktika [Regional Economics: Theory and Practice], 407 (32): 18-30.

Fund for Regional Social Programs 'Our Future' (2019) Atlas praktik razvitija social'nogo predprinimatel'stva sub"ektami Rossijskoj Federacii [Practices in Social Enterprise Development by the Constituent Entities of the Russian Federation Atlas]. Available at: http:// nb-forum.ru/uploads/images/documents/46_9579a.pdf(accessed 11 April 2020).

Ulug C., Horlings L. G. (2019) Connecting Resourcefulness and Social Innovation: Exploring Conditions and Processes in Community Gardens in the Netherlands. Local environment, 24 (3): 147-166. 